1 per cent. solution is usually sufficient to produce anaesthesia without causing conjunctival injection and there is never any mydriasis.

In the treatment of glaucoma if butyn is combined with eserin there is seldom any complaint of twitching or discomfort as is sometimes the case when eserin is used alone.

For all the everyday purposes for which cocain is used in ophthalmic practice butyn appears to be an ideal alternative and one which is devoid of the disadvantages of mydriasis and desiccation of the cornea. When used with other medicaments it is necessary to remember that butyn is incompatible with chlorides.

I have also used butyn as a lotion to relieve pain in herpes of the head and eye and in detachment of the retina.

In view of the widespread illegal administration of cocain, the potentialities of a substitute, devoid of attractions for the drugtaker, should be of value, and if further investigation confirms all that is claimed for butyn, we may hope that the results will have far-reaching effects in reducing the manufacture and repressing the distribution of a drug the illicit use of which causes social calamities.

\title{
THE VISION OF RAILWAYMEN
}

BY

\section{Leonard J. C. Mitchell, M.B., B.S. (Melb.)}

ASSISTANT EXAMINER IN VISION, ETC., VICTORIAN RAIL WAYS

IN order to arrive at some more definite relation between vision as tested by test types under good conditions, and what may be termed " safe vision" from a railway point of view, a series of tests was undertaken recently (1920) at Tottenham (Vic.). Previously (1898) Barrett, Orr and Murray had conducted similar tests, but their data were too meagre to give any definite result, and further, the main object before these experimenters was to prove that what is called a "practical test" is, by itself, very misleading. Later (1914) Gault, Webster and Ryan, in collaboration with Stanley and the writer, conducted a test with a special signal, but it would seem that fallacy was introduced by first reducing with glasses the vision of persons examined. The New South Wales Railway Medical Officers have recorded a test in which the persons examined had vision below normal, but the fallacy of their test was that there was a different background for the various signals used. Bearing in mind these unsatisfactory results, the Tottenham experiment was planned and carried out by H. R. Stanley and the writer, on the afternoon of a cloudy calm 
day, a special standard signal was erected, and the sky was the background throughout the tests.

A standard signal arm (Vic. Rlys.) measures $4 \mathrm{ft} .9$ in. by 10 in., and this arm subtends an angle of five minutes at a distance of 1,085 yards. It might be inferred from Snellen's figures that such a signal arm would be read accurately by a person with $6 / 6$ vision at that distance and no further, but the signal can be read by a normal-sighted person up to a distance of 1.5 miles. Testing vision by test types implies a good illumination, and if we are to form an opinion as to the relation between form vision as tested in the consulting room, and the ability to read signals accurately, it is necessary to test that ability under good conditions of illumination and background. Further, it must be remembered that normal vision is, as a rule, very much better than $6 / 6$, probably $6 / 4$ would be nearer the mark among a large number of normal sighted, and so the results of the test described below are not as surprising as would first appear.

The subjects for examination were locomotive drivers, signalmen and station masters, and each man's vision was tested with test types under the best indoor conditions immediately before the outdoor test was begun. One man, with vision R. 6/12, L. 6/12, combined $6 / 9$, read the signal accurately at 1,760 yards, two others with the same vision were accurate at 1,600 yards, and another at 1,500 yards, men with vision R. $6 / 18$, L. 6/18, combined $6 / 12$, were accurate at from 1,500 to 1,600 yards.

The variations in the ability to read signals amongst men whose vision was the same as when tested indoors, was undoubtedly due to the nature of the error in the individual cases, that is, whether the error was astigmatism or simple hypermetropia. (A temporary light smoke haze obscured the view at one stage, but it was shown that a different visibility of as much as 300 yards was made.)

It is, therefore, clear that we have here a definite relation between the vision of a man whose best vision is $6 / 12$ with both eyes open as tested indoors, and the distance at which he can read signals under good conditions. In other words, a relation between certain degrees of defective vision, and the practical value of such vision from a railway point of view, has been established.

As a matter of railway practice, the signals are so arranged as to come into view at 600 yards distance as a minimum. (This does not apply to automatic signals.) So it would appear that there is an ample margin of safety as regards the distance at which a man with $6 / 18,6 / 18,6 / 12$ vision can see signals.

With regard to the seeing of the signals at night, the lamp glass of a standard signal (Vic. Rlys.) is 5 in. in diameter, but the candle power of the lamps depends much on the cleanliness of the glass, etc. As a point of, light is very much more readily seen than the 
form of a letter, the size of the lamp glass does not bear the same relation to the distance at which the lamp is visible, as in the case of form vision.

The same men were tested with the Edridge-Green lantern immediately after the outdoor test, and it was shown that each man with vision $6 / 18,6 / 18$, both $6 / 12$, was quite accurate with dull red lights. This is our everyday experience, and we hold that if the form vision is not reduced below $6 / 12$ with both eyes open, the colour perception is safe-always excepting toxic amblyopia. A shortened red end to the spectrum should not be diagnosed unless the vision is improved to $6 / 6$, or unless a large (half inch) aperture be used.

Conclusions :- -

(1.) Under ideal conditions a man with vision R. 6/18, L. 6/18, both $6 / 12$, can, with both eyes open, read signals accurately at 1,500 yards.

(2.) Provided that the vision with both eyes open is not below $6 / 12$, colour perception is not dangerously lowered.

NotE.-The complete records of these experiments are in the files of the Railway Department referred to.

\section{REMOVAL OF FILARIA FROM UNDER THE CONJUNCTIVA}

r.Y

\section{E. Charles}

GUJRANWALA

BAGga S/O HiRA, aged 45, resident of Sialkot District, near Jammu State Territory, had, some eight months ago, sudden severe pain in his right eye, and soon after he felt a little swelling on the inner and downward side of his eyeball. The pain of a neuralgic type stopped when cold, but increased in the daytime.

Present condition.-Fairly large swelling on the inner and downward side of the right eye beneath the ocular conjunctiva, redness, watering, pupil dilated, patient in great pain, vision not affected.

Operation.-Under cocain, two days after admission, a small incision with a Graefe's knife was made in the swelling, and a loop of the living worm began to come out of the opening. Just when the head of the thing was being pulled at the patient complained of severe pain, the pull was loosened and the worm began to crawl in again; when just a little of the worm had gone back a sudden pull 